\title{
Analysis of Regenerative Braking In Brushless DC Motor Drive Using Adaptive Neuro Based Fuzzy Inference System
}

\author{
Akhila $\mathbf{M}^{1}$, Ratnan $\mathbf{P}^{2}$ \\ ${ }^{1}$ PG Scholar, Dept. of Electrical and Electronics Engineering, Calicut University, Jyothi Engineering College, Thrissur, India \\ ${ }^{2}$ H.O.D, Dept. of Electrical and Electronics Engineering, Calicut University, Jyothi Engineering College, Thrissur, India
}

\begin{abstract}
The electronically commutated Brushless DC motors are widely used in many industrial applications which increase the need for design of efficient control strategy for these motors. This paper deals with the efficient control mechanisms for these drives using meaningful fuzzy sets and rules. The proposed system includes Brushless DC motor control utilizing the PID control, and improved performance via adaptive neuro based fuzzy control. A simplified current controlled modulation technique for BLDC motor is presented so that one can evaluate the performance of the BLDC motor with PWM Control scheme and effective regenerative braking system has been implemented which has the ability to recover energy An adaptive neuro fuzzy inference system is developed using MATLAB. Simulation results show that ANFIS reaches to the target faster and overcomes the complexity of the problem.
\end{abstract}

Keywords: Brushless DC (BLDC) motor, fuzzy control, Proportional-Integral-Derivative (PID) control, Adaptive neuro based fuzzy inference system (ANFIS), Regenerative Braking System (RBS).

\section{Introduction}

With the emergence of energy crisis, ways of reducing airpollution have become the great challenge. Nowadays, fossil-fueled automobiles have become the major transportation tools. Automakers have made a great effort to find green, energy saving and zero pollution transportation tools. Thus, electric vehicles (EVs) have grown at an accelerated pace lately. However, some of the main difficulties for commercialization of EVs such as driving range still remain. Effective battery utilization and advanced motor control have become an important issue for EVs. A pure electric vehicle (PEV) contains three major parts: the power battery pack (usually in series as an energy-storage unit), the driving motor [can be induction motor (IM), brushless direct-current motor (BLDCM) and switched reluctance machine (SRM)], and the power converter Controller. Among all the driving motors, the brushless direct-current (DC) motor has many advantages over other brush DC motors, IMs and switch reluctance machines. Brushless DC motors works similar to the conventional DC motor with the mechanical commutation replaced by an electronically controlled commutation system. These motors have the rotating permanent magnets and stationary armature. The BLDC motor that are utilized in this control design is star connected BLDC motor. The power distribution is achieved by the intelligent electronic controller. The electronic controller requires rotor position information for proper commutation of currents in the respective stator windings. The rotor position can be sensed using Hall effect sensors embedded in the stator and thus stator windings are energized accordingly. BLDC has the merits of simple structure, high efficiency, electronic commutating device, high starting torque, noiseless operation and high speed range, etc. Hence, the brushless DC motor has been widely used in EVs. Conventional EVs use mechanical brakes to increase the friction of the wheel for deceleration purposes. Thus, the braking kinetic energy is wasted. With this problem in mind, this paper will discuss how to convert the kinetic energy into electrical energy that can be recharged to the battery pack. As a result, regenerative braking can realize both electric brake.

\subsection{Regenerative Braking energy}

Regenerative braking is defined as that in which the motor, which acts as a generator during braking, turns the inertial energy generated in the process of moving into electrical energy that is stored in the storage devices for reuse. At the same time, the motor braking torque is applied to the driving wheels to brake the vehicle through the transmission system.

This paper is organized as follows. BLDC Motor and Control in section II. EV Modelling in section III and MATLAB simulation along with results are explained in section IV. Section V concludes the paper.

\section{BLDC motor and control}

\subsection{BLDC Motors}

A brushless de motor is defined as a permanent synchronous machine with rotor position feedback. The brushless motors are generally controlled using a three phase power semiconductor bridge. The motor requires a rotor position sensor for starting and for providing proper commutation sequence to turn on the power devices in the inverter bridge. Based on the rotor position, the power devices are commutated sequentially every 60 degrees. This eliminates the problems associated with the brush and the commutator arrangement, for example, sparking and wearing out of the commutator brush arrangement, thereby, making a BLDC more rugged as compared to a dc motor. As illustrated in Fig. 1, in a BLDC motor, permanent magnets are mounted on the rotor, with the armature windings being fixed on the stator with a laminated steel core. 


\section{International Journal of Science and Research (IJSR) \\ ISSN (Online): 2319-7064 \\ Index Copernicus Value (2013): 6.14 | Impact Factor (2014): 5.611}

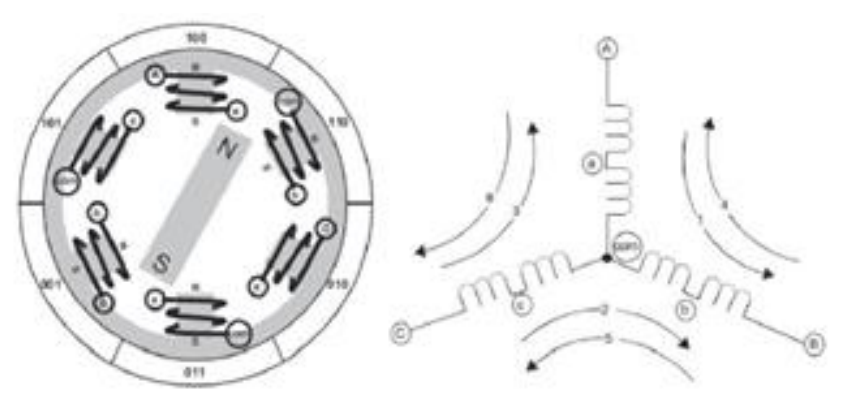

Figure 1: Y-connected BLDC motor construction

\subsection{BLDC Motor Control}

In Power Electronic Converter as shown in Figure 2, two switches are conducting at any instant of time. One switch is from upper side and one from lower side of the bridge. For a star connected system, only two phases are connected to the input and the third phase is left free. Each phase is conducting for a period of 120 electrical degree during flat portion of back EMF. For a period of 60 electrical degree commutation event occurs between phases. The details pertaining to rotor position are needed for proper commutation. By using Hall effect sensors, the position of rotor can be directly detected by observing back EMF of open phase. A BLDC motor uses a dc power supply which is required to provide energy. Hall Effect sensors provide the portion of information need to synchronize the motor excitation with rotor position in order to produce constant torque. It detects the change in magnetic field.. In the commutation system, one that is based on the position of motor identified using feedback sensors: two of three electrical windings are energized at a time.

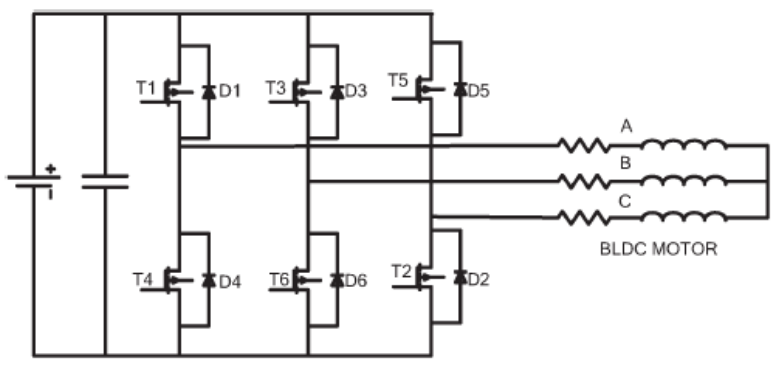

Figure 2: $\mathrm{H}$ bridge inverter circuit

\subsection{MOSFET Control}

The same power circuit in Fig. 2 can be used with an appropriate switching strategy. There are mainly two types of switching independent switching and complementary switching. One simple and efficient method is to independently switch in conjunction with pulse width modulation (PWM) to implement an effective braking control. However, the back EMF of the winding cannot reach the battery voltage due to low speed of BLDC. Hence to raise the dc bus voltage for the energy recovery, a boost circuit is formed by the inductances in the winding. This is done by turning off all MOSFET on the high arms of $\mathrm{H}$ bridge and control the low arms of H-bridge with PWM.

\section{EV Modeling}

The modeling of the EV has been done in MATLAB/ Simulink. The torque request is made by the driver block which propagates through various power train system component and realizes vehicle motion.

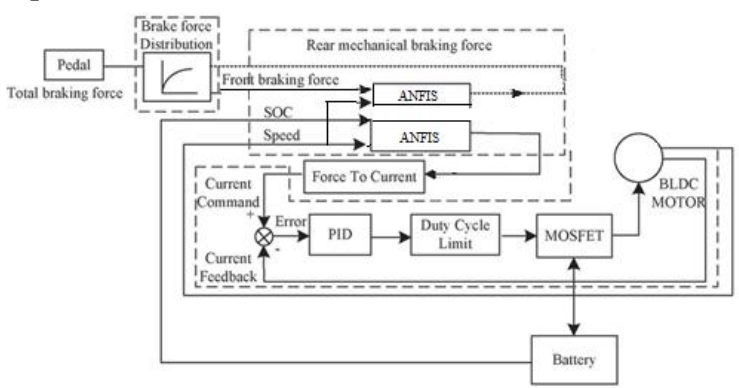

Figure 3. Structure of the control strategy

\subsection{Driver Subsystem :}

The desired drive torque and brake torque is delivered by the driver block through the activation of accelerator and brake pedal.

\subsection{Proportional-Integral Derivative (PID) Control :}

With PID control used primarily to ensure a constant brake torque, different braking force values will give different PWMs. A constant electrical braking torque can be achieved during the fuzzy inference.

\subsection{Brake Strategy Subsystem}

The structure of the control strategy system is shown in Fig 3. According to the fuzzy logic controller, we can obtain the value of the regenerative braking force. Then, the front mechanical braking force, the regenerative braking force, and the rear braking force can be attained.

\subsection{Fuzzy Control}

Braking force distribution in $\mathrm{EVS}$ with regeneration is influenced by many factors, and many parameters are constantly changing, so recycling strategy is difficult to be expressed. The fuzzy logic control strategy for EV braking force distribution can be easily demonstrated by the influence of different factors. The fuzzy control theory is applied to EV braking force distribution. In this control system, the input variables includes the front braking force, the SOC and the EV speed.

\subsection{ANFIS}

The advantage of a neural network is that it can be trained and so can self-learn and self-improve. Combining the two techniques, ANFIS has been proposed. The idea behind neural network and fuzzy inference combination is to design a system that uses a fuzzy system to represent knowledge in an interpretable manner and has the learning ability derived

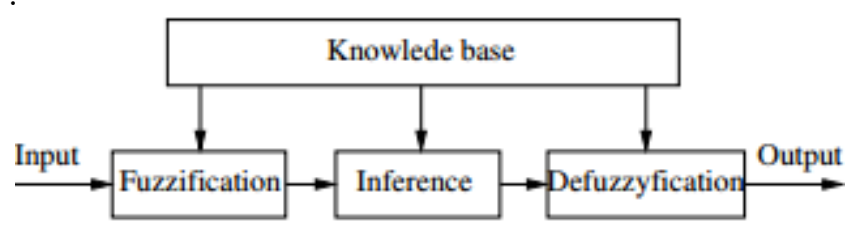

Figure 4 . ANFIS

\section{Volume 4 Issue 12, December 2015}




\section{International Journal of Science and Research (IJSR) \\ ISSN (Online): 2319-7064}

Index Copernicus Value (2013): 6.14 | Impact Factor (2014): 5.611

Adaptive Neuro based Fuzzy Inference System from a neural network that can adjust the membership functions parameters and linguistic rules directly from data in order to enhance the system performance. It implements a Sugeno fuzzy inference system for a systematic approach to generating fuzzy rules from a given input output dataset. The ANFIS architecture contains a five-layer feed forward neural network as shown.

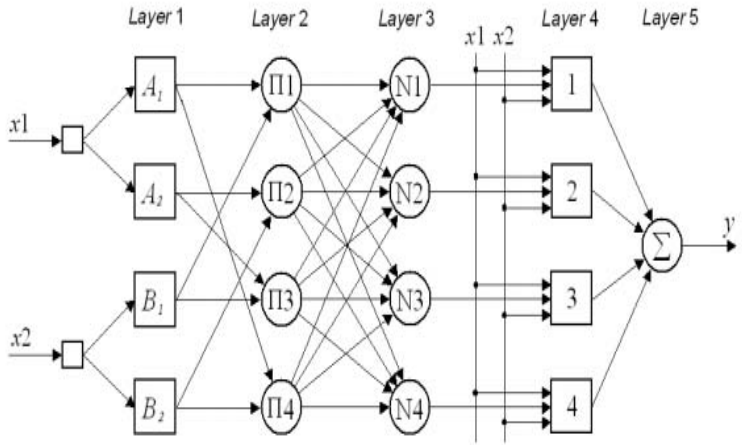

Figure 5: Five layer architecture

\section{Implementation and Simulation Results}

With the above design consideration the simulation has been done and the result is presented here. Speed is set at 1250 rpm and load torque disturbance is applied at $3 \mathrm{sec}$ and the braking is obtained at the set speed

Table 1: BLDC motor specifications

\begin{tabular}{|c|c|}
\hline Parameter & Value \\
\hline Nominal voltage & 72 \\
\hline Speed & 2800 \\
\hline Current & 200 \\
\hline Rated power & 7 \\
\hline
\end{tabular}

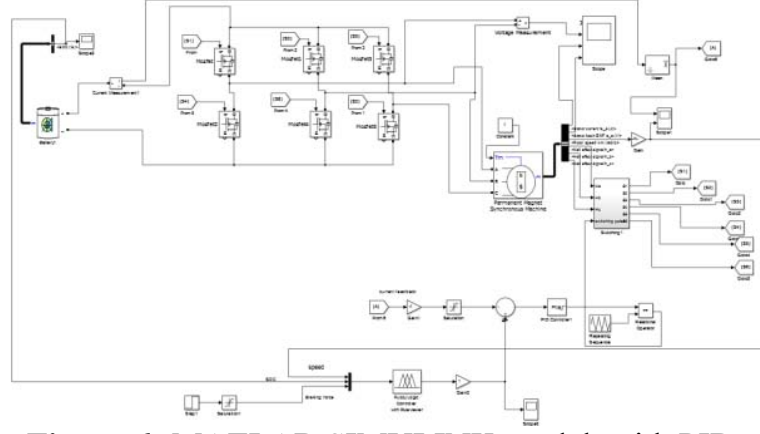

Figure 6: MATLAB SIMULINK model with PID and fuzzy control

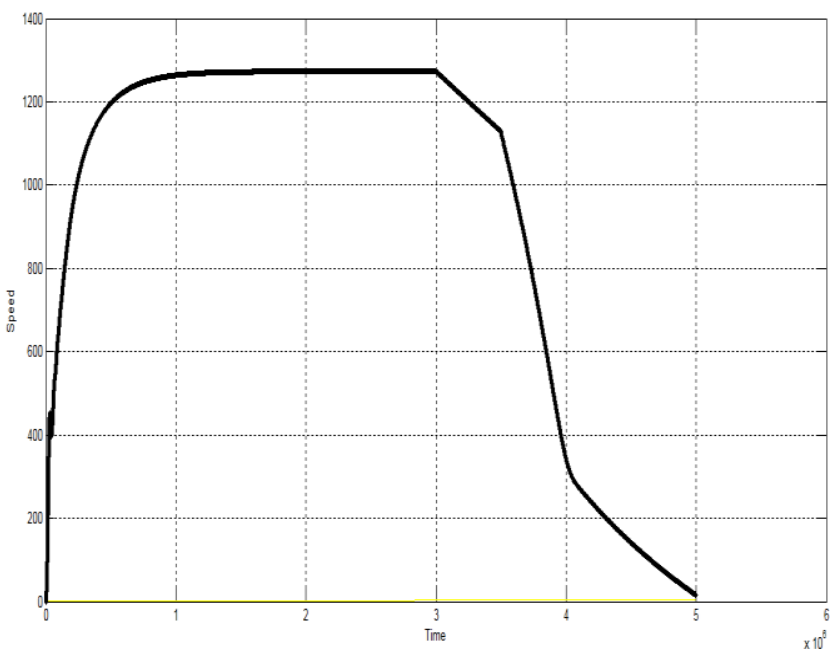

Figure 7: Controlled braking

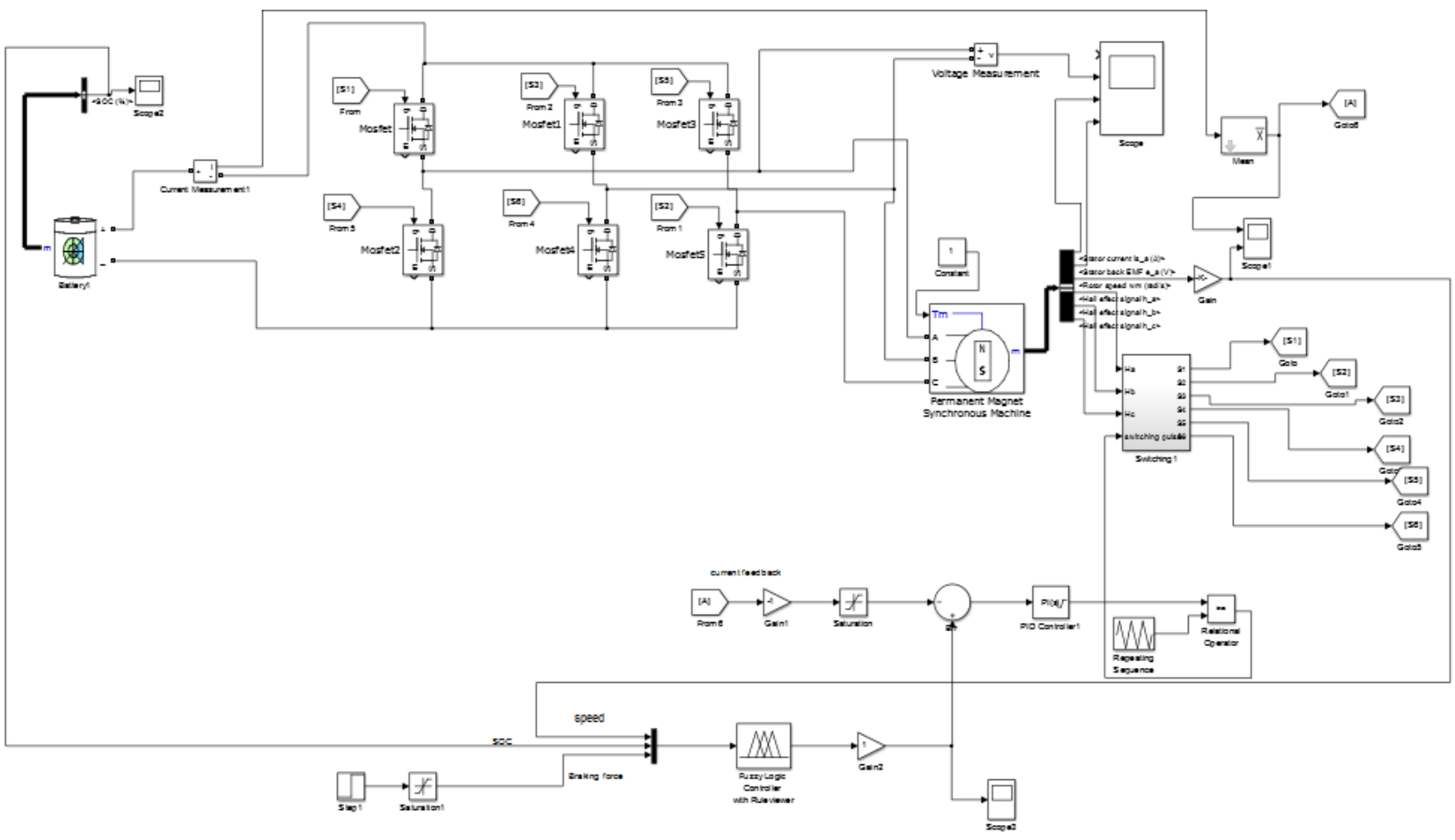

Figure 8: MATLAB SIMULINK model with PID and adaptive neuro based fuzzy inference system

\section{Volume 4 Issue 12, December 2015}




\section{International Journal of Science and Research (IJSR) ISSN (Online): 2319-7064}

Index Copernicus Value (2013): 6.14 | Impact Factor (2014): 5.611

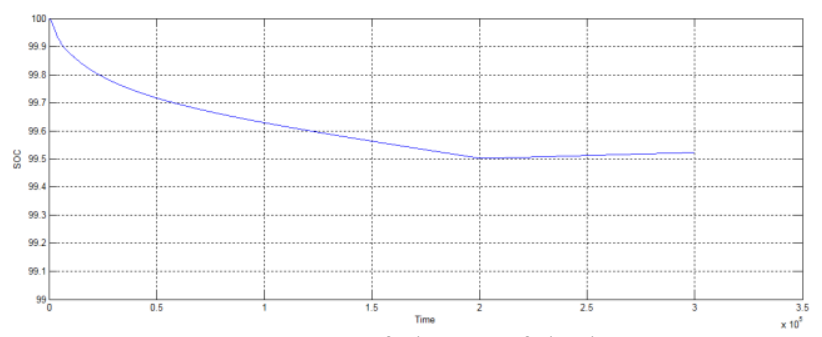

Figure 9: State of charge of the battery

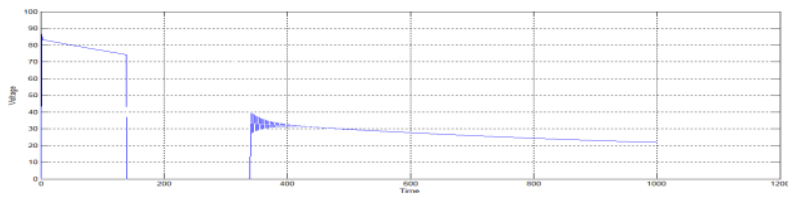

Figure 10: DC Bus voltage

The voltage waveforms during the regeneration state is shown. The dc bus voltage keeps a high value at the regenerative region. The EV will switch to mechanical braking if the speed is too low.

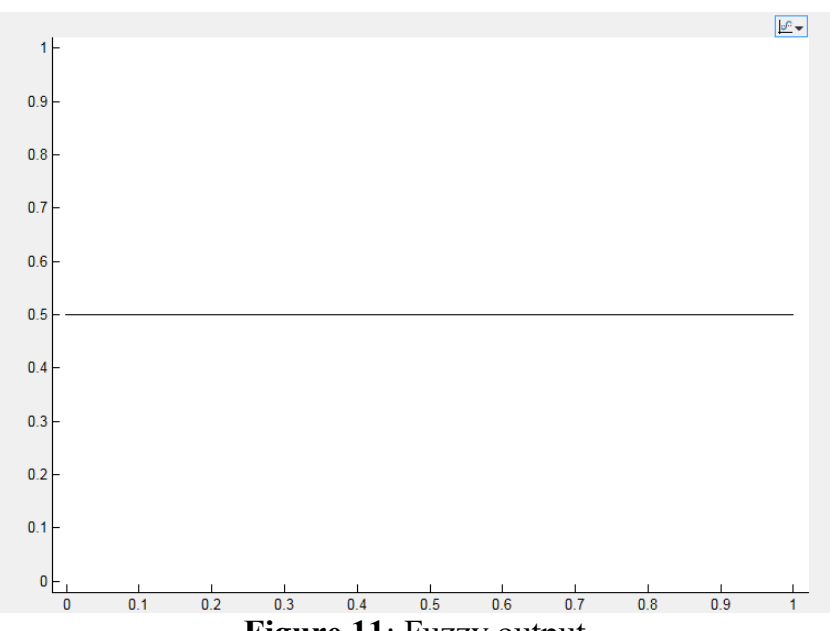

Figure 11: Fuzzy output

Using ANFIS errors have been reduced as maximum number of trials have been considered to get a fuzzy output of 0.5 .

As explained above, the PWM inverter modeling is based on the switching function concept. Fig 9 shows the battery SOC which reduces during the braking. A controlled braking as illustrated in Fig 7 is thus obtained by the distribution of braking forces by fuzzy control and current sensing control.

\section{Conclusion}

This paper has presented the RBS of EVs which are driven by the BLDC motor. The performance of the EVs' regenerative brake system has been realized by our control scheme which has been implemented both in the simulation. By combining adaptive neuro based fuzzy control and PID control methods which are both sophisticated methods, RBS can distribute the mechanical braking force and electrical braking force dynamically. PID control is has been adapted to adjust the BLDC motor PWM duty to obtain the constant brake torque. PID control is faster than fuzzy control, so the two methods combined together can realize the smooth transitions. Therefore, it can be concluded that this RBS has the ability to recover energy and ensure the safety of braking in.

\section{References}

[1] Xiaohong Nian, Fei Peng, and Hang Zhang, "Regenerative Braking System of Electric Vehicle Driven by Brushless DC Motor," Ieee Transactions On Industrial Electronics, Vol. 61, No. 10, October 2014

[2] P. J. Grbovic, P. Delarue, P. Le Moigne, and P. Bartholomeus, "A bidirectional three-level dc-dc converter for the ultra-capacitor applications," IEEE Trans. Ind. Electron., vol. 57, no. 10, pp. 3415-3430, Oct. 2010.

[3] F. Wang, X. Yin, H. Luo, and Y. Huang, "A series regenerative braking control strategy based on hybridpower," in Proc. Int. Conf. CDCIEM, 2012, pp. 65-69.

[4] N. Mutoh and Y. Nakano, "Dynamics of front-and-rearwheelindependent-drive-type electric vehicles at the time of failure," IEEE Trans. Ind. Electron., vol. 59, no. 3, pp. 1488-1499, Mar. 2012.

[5] M. Cheng, W. Hua, J. Zhang, and W. Zhao, "Overview of stator permanent magnet brushless machines," IEEE Trans. Ind. Electron., vol. 58, no. 11, pp. 5087-5101, Nov. 2011.

[6] Y.Wang and Z. Deng, "Hybrid excitation topologies and control strategies of stator permanent magnet machines for dc power system," IEEE Trans. Ind. Electron., vol. 59, no. 12, pp. 4601-4616, Dec. 2012.

[7] C. Sheeba Joice, S. R. Paranjothi, and V. J. Senthil Kumar, "Digital control strategy for four quadrant operation of three phase BLDC motor with load variations," IEEE Trans. Ind. Informat., vol. 9, no. 2, pp. 974-982, May 2013

[8] A. Sathyan, N. Milivojevic, Y.-J. Lee, M. Krishnamurthy, and A. Emadi, "An FPGA-based novel digital PWM control scheme for BLDC motor drives,' IEEE Trans. Ind. Electron., vol. 56, no. 8, pp. 3040 3049, Aug. 2009.

[9] N. Keskar, M. Batello, A. Guerra, and A. Gorgerino, "Power Loss Estimation Segundo, CA, USA, Rep. AN1048, Feb. 2010.

[10]K. Yoong, Y. H. Gan, G. D. Gan, C. K. Leong, Z. Y. Phuan, B. K. Cheah, and K. W. Chew, "Studies of regenerative braking in electric vehicle," in Proc. IEEE Conf. Sustainable Utilization Develop. Eng. Technol., Nov. 20/21, 2010, pp. 40-41.

[11] J. M. J. Yang, H. L. Jhou, B. Y. Ma, and K. K. Shyu, “A cost-effective method of electric brake with energy regeneration for electric vehicles," IEEE Trans. Ind. Electron., vol. 56, no. 6, pp. 2203-2212, Jun. 2009.

$[12] N$. Mutoh, "Driving and braking torque distribution methods for front and rear-wheel-independent drivetype electric vehicles on roads with low friction coefficient," IEEE Trans. Ind. Electron., vol. 59, no. 10, pp. 3919-3933, Oct. 2012. 